\title{
Pharmacognostic Specification and Coumarin Content of Alyxia reinwardtii Inner Bark
}

\author{
Kanyarat Peng-ngummuang ${ }^{1, a}$, Chanida Palanuvej ${ }^{1, b}$, and Nijsiri Ruangrungsi ${ }^{1,2}$ \\ 1 College of Public Health Sciences, Chulalongkorn University, Bangkok 10330, Thailand \\ 2 Faculty of Pharmacy, Rangsit University, Patumthani 12000, Thailand \\ E-mail: anadeshiko-kiwi@hotmail.com, bchanida.p@chula.ac.th (Corresponding author)
}

\begin{abstract}
Alyxia reinwardtii Blume is used in traditional medicine for a long time. This study was carried out to investigate the standardization parameters by qualitative and quantitative analyses as well as coumarin content of $A$. reinwardtii inner bark. Loss on drying, total ash, acid-insoluble ash, water soluble extractives, ethanol soluble extractives and moisture contents were found to be $8.1 \pm 0.2,7.6 \pm 0.1,1.4 \pm 0.1,16.5 \pm 0.1,8.9 \pm$ 0.3 and $11.9 \pm 0.2 \%$ by dry weight, respectively. Coumarin in dichloromethane extract of A. reinwardtii inner bark was analysed by thin layer chromatography (TLC) using silica gel $60 \mathrm{~F}_{254}$ as stationary phase, hexane and ethyl acetate $(1: 1)$ as mobile phase. The content was evaluated by image analysis using image $\mathrm{J}$ software. The regression line of method was polynomial in range of $0.075-1.2 \mathrm{mg} / \mathrm{spot}$, and correlation coefficients $\left(\mathrm{R}^{2}\right)$ were 0.99 . The repeatability and intermediate precisions were between $0.5-7.1 \%$ RSD. The percent recovery was found to be $96.8-107.3 \%$. The robustness evaluated by slightly variation in mobile phase ratio was $1.3 \%$ RSD. Limit of detection (LOD) and limit of quantitation (LOQ) were 0.05 and $0.16 \mathrm{mg} / \mathrm{spot}$ respectively. The coumarin content in $A$. reinwardtii inner bark crude drug was found to be $0.75 \pm 0.01 \%$ by dry weight. This study provided pharmacognostic specification toward fundamental standardization of $A$. reinwardtii inner bark. Additionally, the simple TLC with image analysis can be applied to quantitatively determine coumarin in plant material.
\end{abstract}

Keywords: Coumarin, Alyxia reinwardtii Blume, TLC image analysis.

ENGINEERING JOURNAL Volume 19 Issue 3

Received 27 May 2015

Accepted 27 May 2015

Published 5 June 2015

Online at http://www.engj.org/

DOI:10.4186/ej.2015.19.3.15 


\section{Introduction}

Alyxia reinwardtii Blume is a brush wood that widely found in Thailand, Indonesia, Malaysia, Philippines and Vietnam. It is commonly known in Thai as "Cha-lood". According to traditional Thai medicine, the flower has been used for treating mental confusion and hallucination associated with high fever. Moreover, the bark has been used for treatment of fainting, flatulence and fever. A. reinwardtii has been reported to contain three classes of secondary metabolites, i.e., coumarin and its derivatives, trimeric-iridoid diglucoside and iridolactone [1]. Coumarin has various pharmacological properties such as anti-nociceptive, bronchodilator and anti-inflammatory properties [2]. Although, A. reinwardtii inner bark is widely used in traditional Thai medicine but its pharmacognostic specification has not been established. Thin layer chromatography (TLC) is the method conventionally used for qualitative investigation of the active compounds in plant extracts because of the ease, simplicity and rapidity. TLC image analysis is a computerised method that used to quantitate the pixel intensity of each compound band on TLC image, transform to each chromatographic peak and calculate the peak area [3, 4]. ImageJ is a public domain Java image processing open source software which can be used for TLC image analysis due to its easily applicable [5]. This study aims to investigate the standardization parameters of $A$. reinwardtii inner bark in Thailand with the special reference to coumarin marker.

\section{Materials and Methods}

\subsection{Plant Materials and Chemicals}

The inner bark of $A$. reinwardtii was collected from 15 various sources throughout Thailand. Voucher specimens were authenticated by one of the authors (Ruangrungsi N.) and deposited at College of Public Health Sciences, Chulalongkorn University, Thailand. Standard coumarin was purchased from SigmaAldrich, USA. The chemicals were analytical grade.

\subsection{Crude Extract Preparation}

Inner bark of $A$. reinwardtii was dried and ground to powders. The powders were exhaustively extracted with dichloromethane by Soxhlet apparatus. The extract yields were weighed and recorded.

\subsection{Determination of Pharmacognostic Specification}

The pharmacognostic parameters including macroscopic characters, microscopic characters, ash values (total ash and acid-insoluble ash), loss on drying, moisture content, water and ethanol extractives were carried out according to "Quality Control Methods for Medicinal Plant Materials" which was guided by WHO [6]. The parameters were evaluated as grand mean \pm pool SD. Each sample was performed in triplicate.

\subsection{Determination of Coumarin Contents}

Five milligrams of crude extract were dissolved with $1 \mathrm{ml}$ of dichloromethane containing $10 \%$ methanol. Five microliters of extract solution as well as coumarin standard solution were applied on the same TLC plate (silica gel $60 \mathrm{~F}_{254}$ ). The TLC plate was developed in TLC chamber with a mobile phase consisted of hexane and ethyl acetate (1:1). The developed TLC plate was photographed under ultraviolet light at $254 \mathrm{~nm}$ and saved as tiff file. The color intensity of coumarin band was transformed to chromatographic peak area by imageJ software. The contents of coumarin in $A$. reinwardtii extracts were calculated based on external standard method. The test was done in triplicate.

\subsection{Method Validation}

Accuracy, precision, limit of detection (LOD), limit of quantitation (LOQ), range and robustness were evaluated according to ICH guideline [7]. 


\section{Results and Discussion}

"A. reinwardtii is a ground climber; leaves opposite; inflorescence axillary or terminal, $1-3.5 \mathrm{~cm}$ long; corolla tube columnar, white, cream, or white with a buff coloured tube and white lobes; fruit with 1-2 articles in each string, ellipsoid or globose, maturing black" [8]. The A. reinwardtii fruiting branch and inflorescence drawing were exhibited in figure 1. Pharmacognostic specification is primary important tool for identification, authentication and standardization of herbal medicines. The pharmacognostic parameters of A. reinwardtii inner bark were shown in table 1 . The histological and anatomical characteristics of $A$. reinwardtii inner bark were drawn and shown in figure 1. The data from this study could be used as standard criteria of this crude drug. Ash contents were referred to inorganic components of plant materials. Acid insoluble ash value of this plant material was not exceeding $2 \%$ [9]. Higher ash values indicated contamination and plant material adulteration. Water soluble extractive yield is higher than ethanol soluble extractive. Extractive matters in specified solvents indicated chemical components in crude drug. Fewer extractive matters than the specified solvent indicated inferiority of crude drug. According to previous study, the coumarin content in dried stem of $A$. reinwardtii was $0.045 \%$ by weight ( $2.15 \mathrm{~g}$ of coumarin isolated from $4.8 \mathrm{~kg}$ of dried stem) [1]. By TLC image analysis in this study, coumarin content in dried inner bark was $0.75 \pm 0.01 \%$ by weight. The different parts of the plant might contain various coumarin contents. The method validity was demonstrated in Table 2 . The accuracy was performed by recovery of spiking known three concentrations of standard coumarin in sample matrix. The recovery values were within acceptable limits (96.8-107.3\%). The repeatability or intra-day precision and the intermediate precision or inter-day precision were less than $8 \%$. The precision of coumarin quantitative analysis by TLC image analysis method was conducted by determination of 4 concentrations $\times 3$ replicates at the same and difference days of tests. LOD and LOQ were calculated based on the residual standard deviation of a regression line. The LOD value, regard as the lowest concentration of analyse in a sample which could be detected was found to be $0.05 \mathrm{mg} / \mathrm{spot}$. The LOQ value, regard as the lowest concentration of analyse in a sample which could be quantitatively determined was $0.16 \mathrm{mg} / \mathrm{spot}$. The robustness was estimated by analysis of results obtain after deliberate variation of mobile phase ratio. This study display that there were no differences $(\% \mathrm{RSD}<5)$ in the peak area and retardation factor of coumarin. The calibration curve was polynomial with the range of $0.075-1.2 \mathrm{mg} / \mathrm{spot}$ (Figure 2). The results from method validation indicated that TLC image analysis could be efficient, reliable and suitable technique for quantitative analysis of coumarin in A. reinwardtii inner bark.

Table 1. The pharmacognostic parameters of Alyxia reinwardtii inner bark.

\begin{tabular}{lc}
\hline Specification & Content (\% dry weight) $*$ \\
\hline Loss on drying & $8.1 \pm 0.2$ \\
Total ash & $7.6 \pm 0.1$ \\
Acid-insoluble ash & $1.4 \pm 0.1$ \\
Ethanol soluble extractives & $8.9 \pm 0.3$ \\
Water soluble extractives & $16.5 \pm 0.1$ \\
Moisture & $11.9 \pm 0.2$ \\
\hline \multicolumn{2}{l}{$*$ Grand mean \pm Pool SD }
\end{tabular}

Table 2. Method validation of TLC image analysis of coumarin in Alyxia reinwardtii inner bark.

\begin{tabular}{lc}
\hline Parameter & Validity \\
\hline Accuracy & $96.8-107.3 \%$ recovery \\
Precision & $0.5-7.1 \%$ RSD \\
Robustness & $1.27 \%$ RSD \\
Limit of detection & $0.05 \mathrm{mg} / \mathrm{spot}$ \\
Limit of quantitation & $0.16 \mathrm{mg} / \mathrm{spot}$ \\
\hline
\end{tabular}




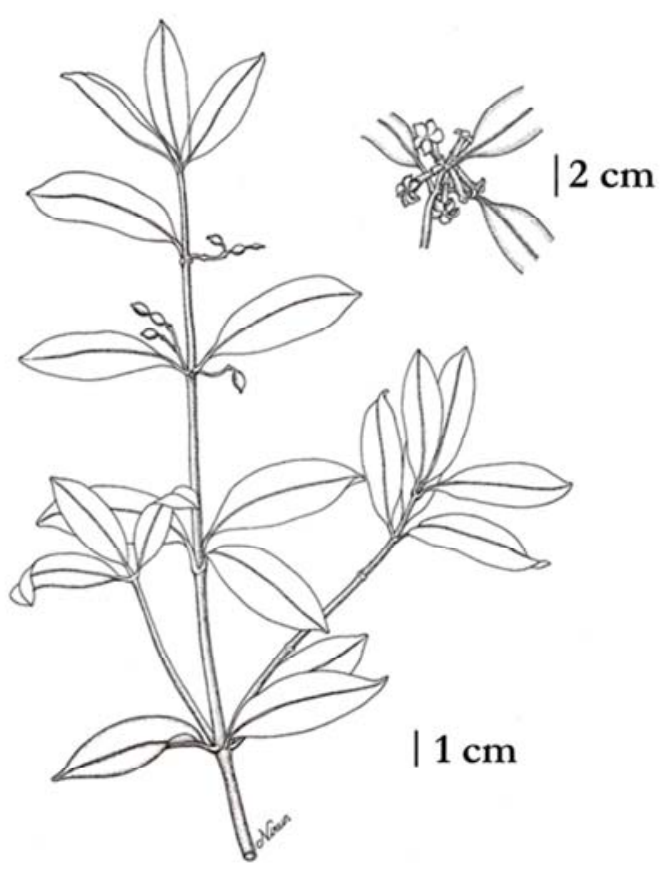

Fruiting branch and Inflorescence

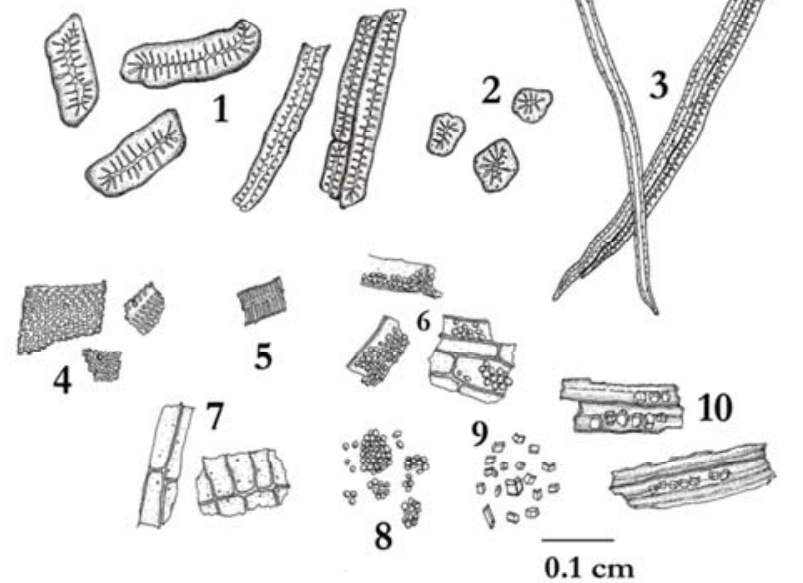

Histological character of inner bark power

1. Sclereid, longitudinal view, 2. Sclereid, transverse view, 3 . Fragment of fiber, 4.Fragment of pitted vessel, 5. Fragment of reticulated vessel, 6. Parenchyma containing starch granule, 7. Fragment of parenchyma, 8. Starch granule, 9. Prism crystals of calcium oxalate, 10. Calcium oxalate prism sheath

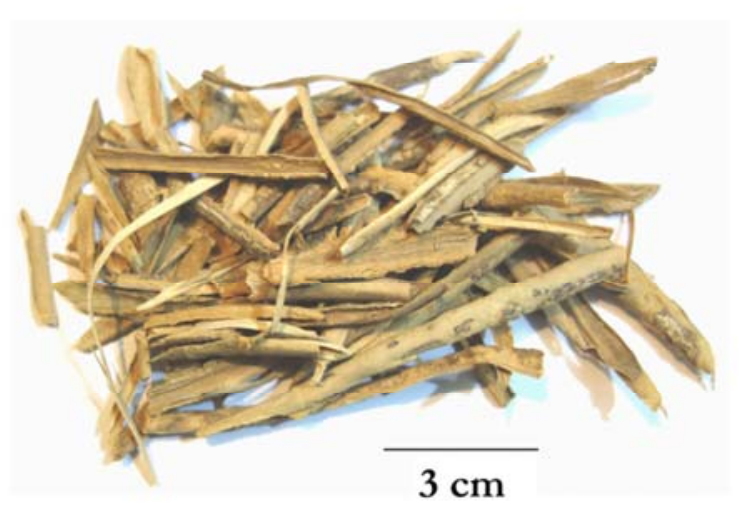

Crude drug

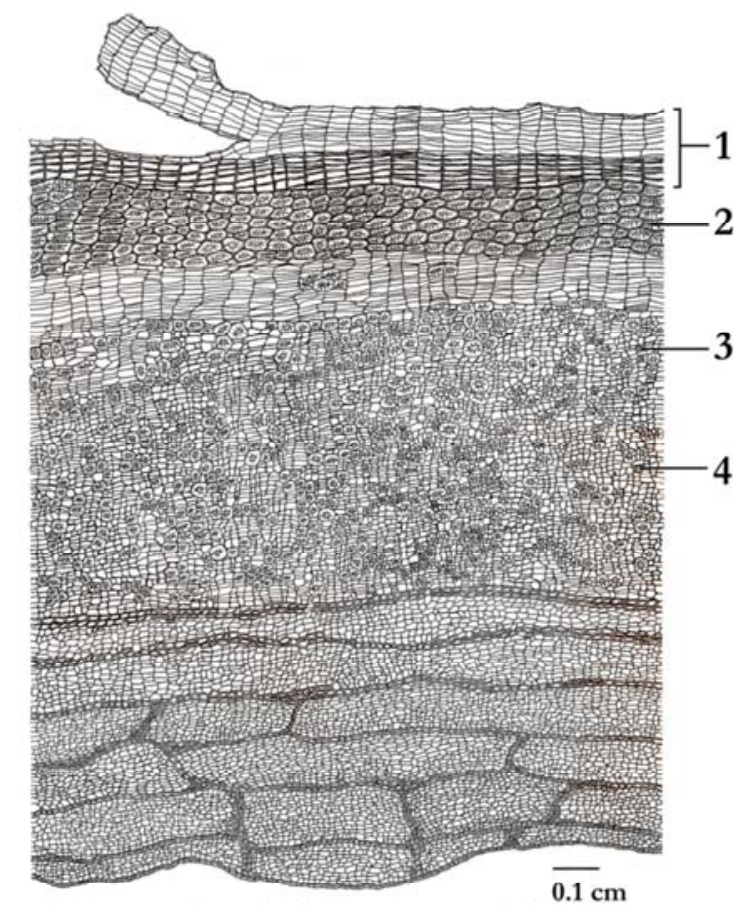

Anatomical character of inner bark transverse section

1. Periderm, 2. Sclereid, 3. Parenchyma containing starch granule, 4. Parenchyma containing prism crystal of calcium oxalate

Fig. 1. Macroscopic and microscopic characteristics of Alyxia reinwardtii. 


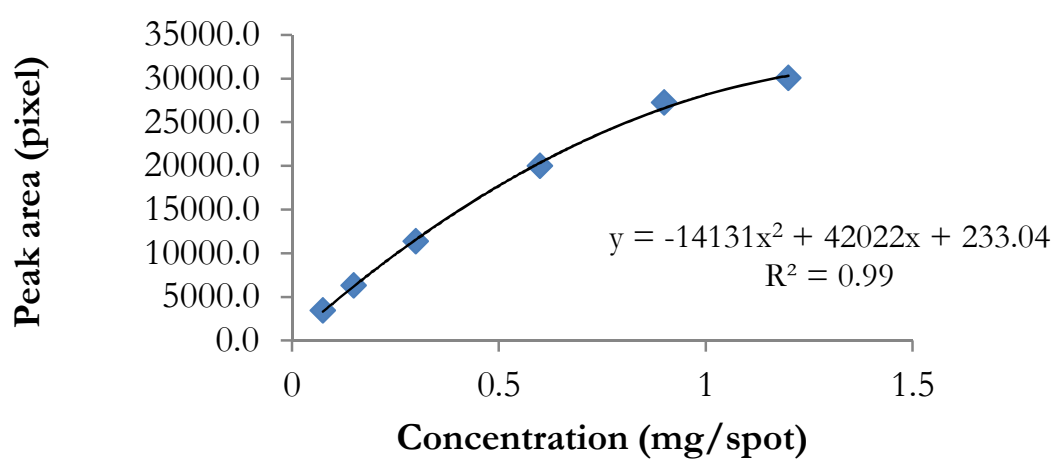

Fig. 2. The calibration curve of coumarin standard.

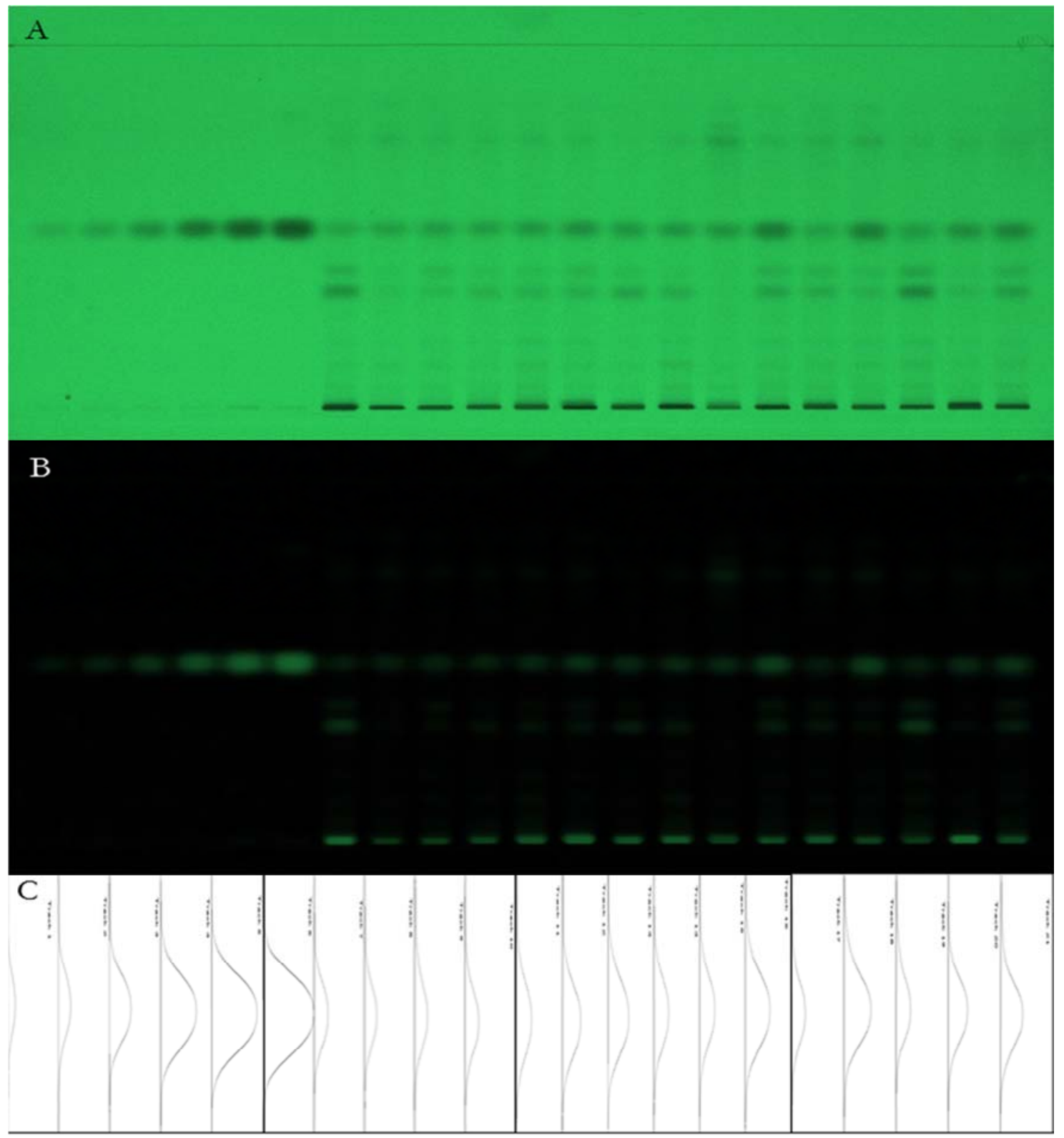

Fig 3. The TLC plate developed with hexane: ethyl acetate (1:1) photographed under UV $254 \mathrm{~nm}$ (A), with subtract background (B), chromatographic peak area by imageJ software (C); Track 1-6 were standard coumarin, Track 7-21 were sample from 15 different sources throughout Thailand. 


\section{Conclusion}

Quality control and standardization of herbal crude drug are important for quality herbal medicine. In this study, the pharmacognostic specifications of $A$. reinwardtii inner bark in Thailand were established. Furthermore, conventional TLC combined with image analysis software could be used for quantification of coumarin in this crude drug.

\section{Acknowledgement}

The authors thank all staff members of College of Public Health Sciences, Faculty of Pharmaceutical Sciences, Chulalongkorn University for assistance and instrument supports.

\section{References}

[1] J. Rattanapan, J. Sichaem and S. Tip-pyang, "Chemical constituents and antioxidant activity from the stems of Alyxia reinwardtii,” Rec. Nat. Prod., vol. 6, no. 3, pp. 288-291, 2012.

[2] L. K. A. M. Leal, A. A. G. Ferreia, G. A. Bezerra, F. J. A. Matos and G. S. B. Viana, “Antinoceptive, anti-inflamatory and bronchodilator activities of Brazilian medicinal plants containing coumarin : a comparative study," J Ethnopharmacol, no. 70, pp. 151-159, 2000.

[3] S. Mokolrat, C. Palanuvej, N. Ruangrungsi, "Thin layer chromatography and image analysis of selected liriodenine bearing plants in Thailand," J Health Res, vol. 27, no. 2, pp. 67-72, 2013.

[4] P. Phattanawasin, U. Sotanaphun, L. Sriphong, "Validate TLC-image analysis method for simultaneous quantification of curcuminoids in Curcuma longa," Chromatographia, no. 69, pp. 397-400, 2009.

[5] M. Olech, L. Komsta, R. Nowak, L. Ciesla, M. Waksmundzka-Hajnos, "Investigation of antiradical activity of plant material by thin layer chromatography with image processing," Food Chem , vol. 132, pp. 549-553, 2012.

[6] World Health Organization, "Determination of foreign matter," in Quality control methods for medicinal plant materials. Geneva : WHO, pp. 9-33, 2011.

[7] ICH Harmonized Tripartide Guideline, "Validation of analytical procedures: Text and methodology, Q2 (R1)," in the International Conference on Harmonisation of Technical Requirements for Registration of pharmaceuticals for Human Use. Geneva, 2005.

[8] Flora of China Editorial Committee, "Flora of China (Gentianaceae through Boraginaceae" in C. Y. Wu, P. H. Raven \& D. Y. Hong (eds.), Fl. China Science Press \& Missouri Botanical Garden Press, Benijing \& St. Louis, Vol. 16, pp. 1479, 1995.

[9] K. P. Mukherjee, M. Venkatesh, V. Kumar, "Development of Standardization Parameters" in quality control of herbal drugs, An approach to Evaluation of Botanicals, India, pp. 189-191, 2002. 